مقايسه ميزان ماندكارى در درمان در سه روش درمان نكهلارنده با متادون، تنتور اييوم و بويره نورفين در بيماران مراكز ترك اعتياد

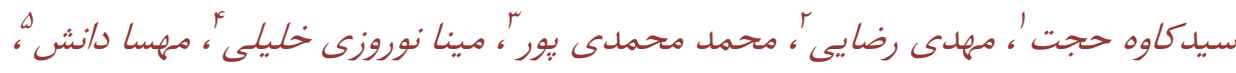 \\ سيد اسماعيل حاتمى
}

'استاديار روانيزشكى، مركز تحقيقات اعتياد و علوم رفتارى، دانشكاه علوم يزشكى خراسان شمالى، بجنورد، ايران.

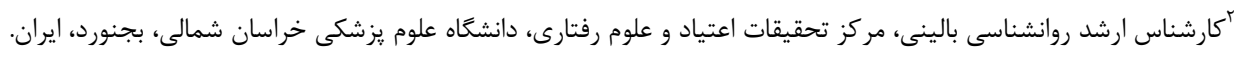

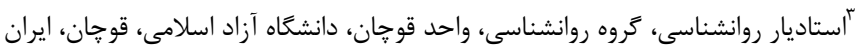

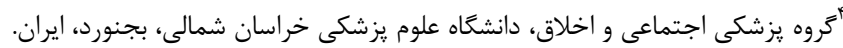

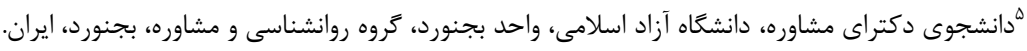

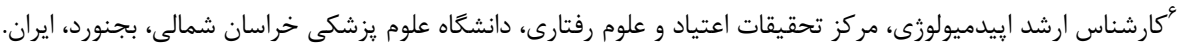

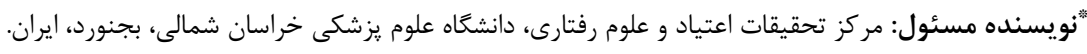

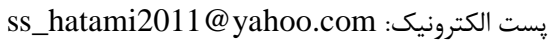

حكبه

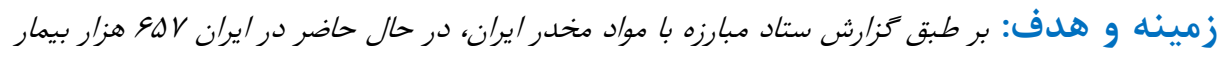

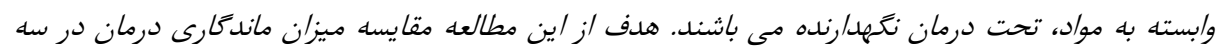

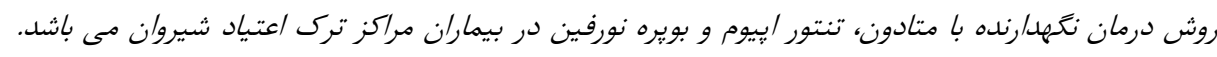

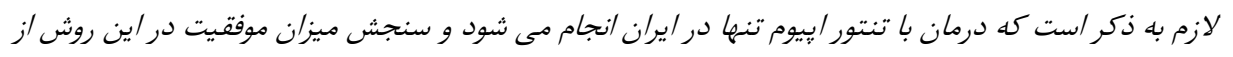

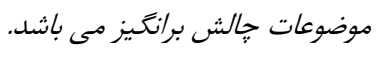

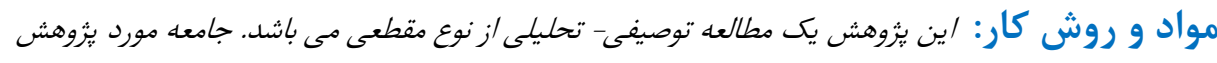

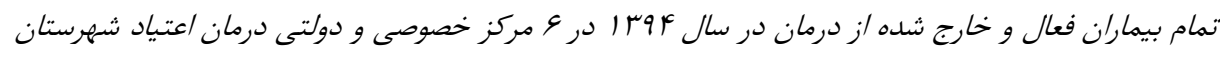

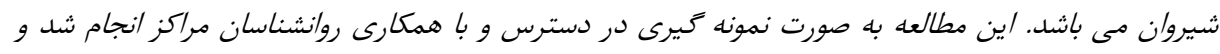

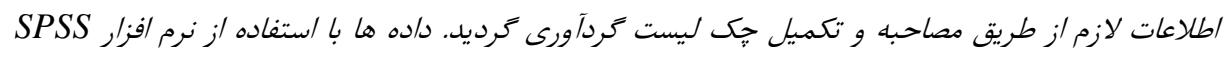

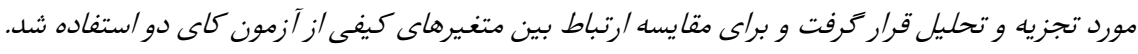

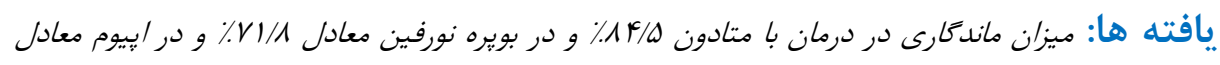

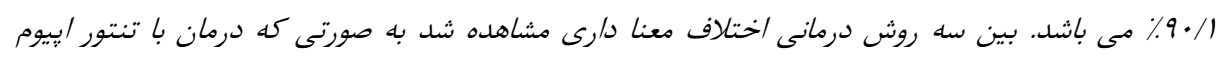

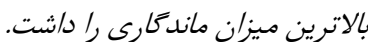

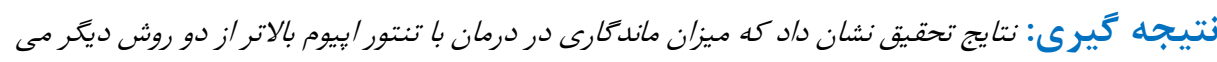

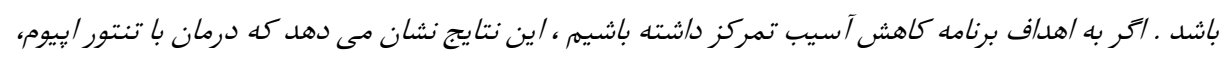

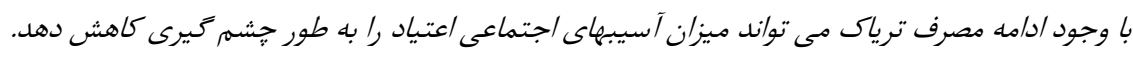

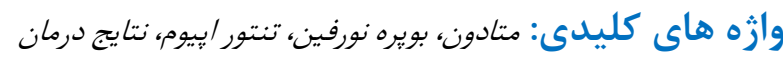

DOI: $10.18869 /$ acadpub.jnkums.8.2.245

Cite this article as: Hojjat $S$, Rezaei $M$, mohamadipoor M, Norozi Khalili M, Danesh $M$, Hatami $S$. The comparison of Retention in three methods with Methadone, opium and Buprenorphine in patients admitted to addiction treatment centers . jnkums. 2016; 8 (2) :245-256 
[^] تحقيقات بارنت' نشان داد بيمارانى كه وارد درمان

مقلهمه

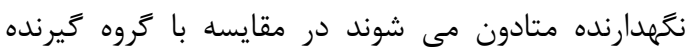

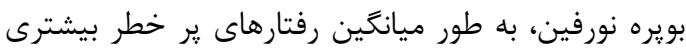

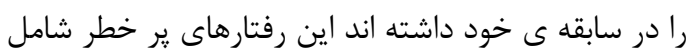
روش هاى جنسى نايمن و مصرف تزريقى بود كه يس إز از

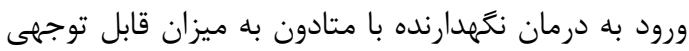

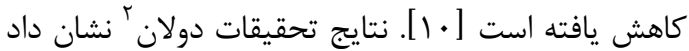

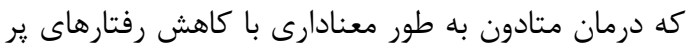

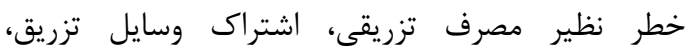
رفتارهاى جنسى نايمن و انجام سكس براى يول ئرل يا موراد

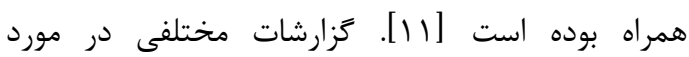

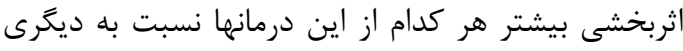

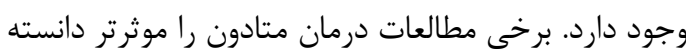

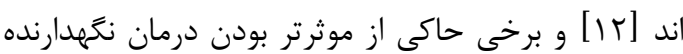

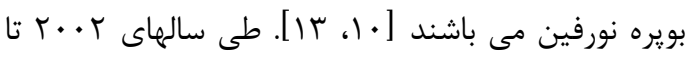

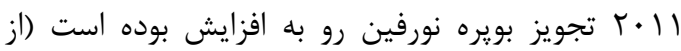

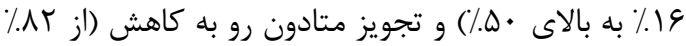

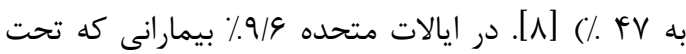

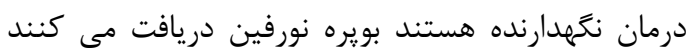

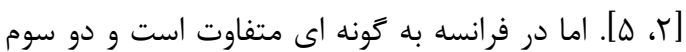
بيماران وابسته به مواد إييوئيدى (نزديك به صدانه صد هزائ

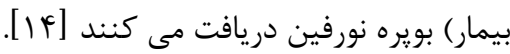

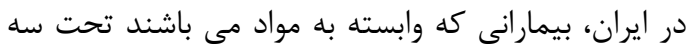

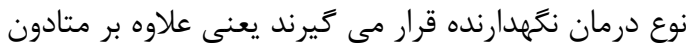

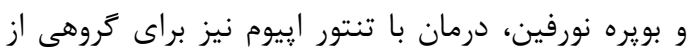

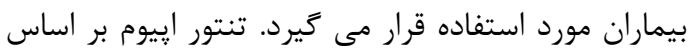

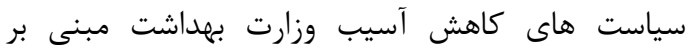

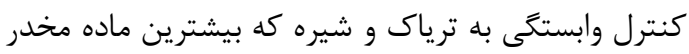

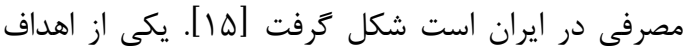

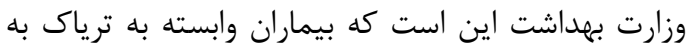

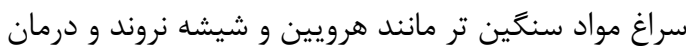

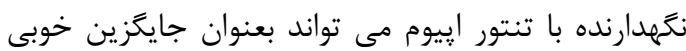

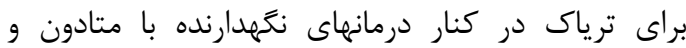

بويرونورفين مورد استفاده قرار بكيرد [عائ درئ.

مصرف مواد يكى از جدى ترين مشكلات بهداشتى و

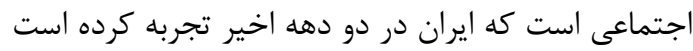

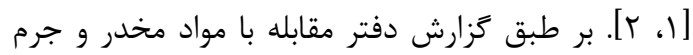
سازمان ملل متحد بيشترين اعتياد جهان در ايران كزارش

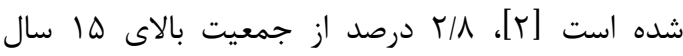

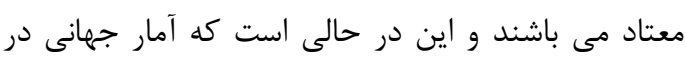

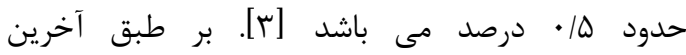

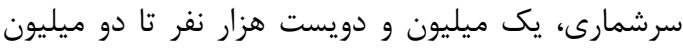

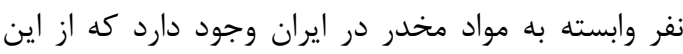

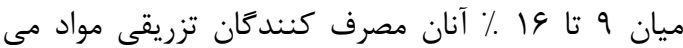

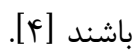

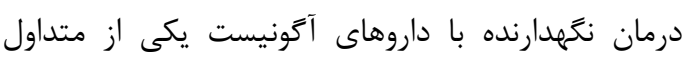

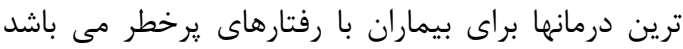

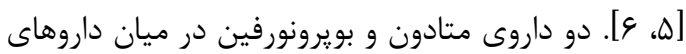
اكونيست از همه بيشتر مورد استفاده قرار مئ دئ ديرد.

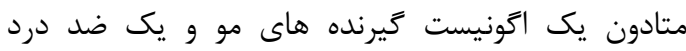
تركيبى است كه قدرت جسبندگى بالاترى به گيرنده هاى

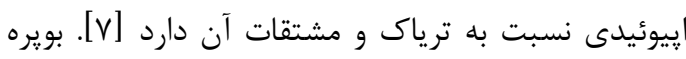

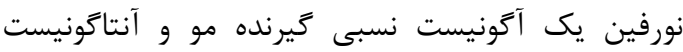

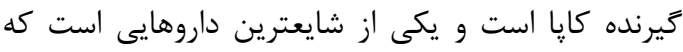
براى سم زدايى بيماران وابسته به مواد استفاده مى شود إنى داني

انتخاب نوع درمان نتحهدارنده (متادون يا بويرونورفين يا

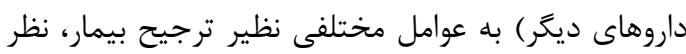

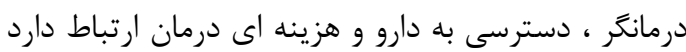

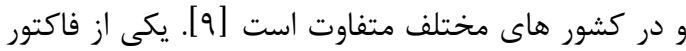

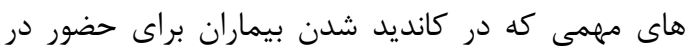

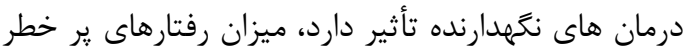

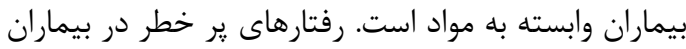

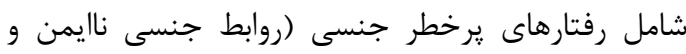

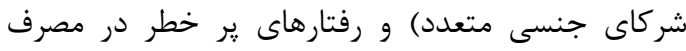
(مصرف تزريقى و استفاده از سوزن اشتراكى) مى باشد. شواهد نشان مى دهد كه هر دو داروى متادون و بويره نورفين در كاهش رفتارهاى ير خطر بيماران موثر بوده اند دون 
درمان نكمهدارنده دريافتى و طول مدت تحت درمان

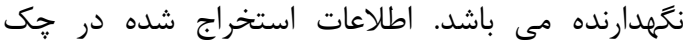

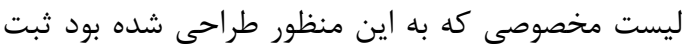
كرديد. جهت رعايت موازين اخلاق در يزوهش و وركائ حفظ رازدارى بيماران، كليه جك ليستها بدون نام بوده و تنها

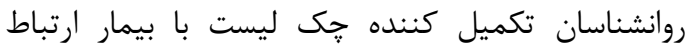

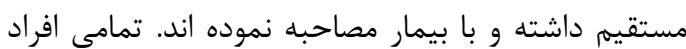

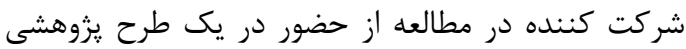

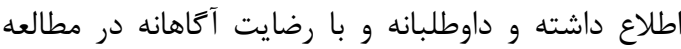

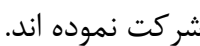

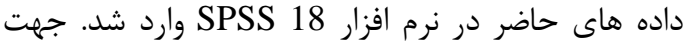
تجزيه تحليل داده ها، آمار توصيفى (فراوانى و درصد براى داى

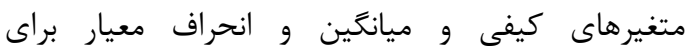
متغيرهاى كمى) مورد استفاده قرار كرفت. براى مقايسه ارتباط بين متغيرهاى كيفى در كروههاى تحت درائ درمان

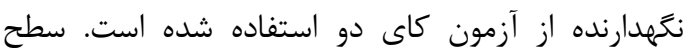
معنادارى در اين مطالعه هـ/• در نظر ترفته شد.

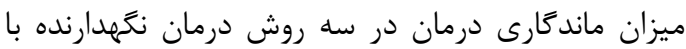

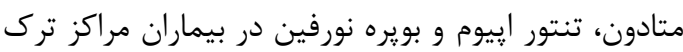
اعتياد شهرستان شيروان بر اساس نسبت كل بيماران فعال

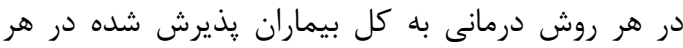
روش درمانى سنجيده شد.

\section{يافته ها}

در اين مطالعه |ه| بيمار از ادامه درمانهاى نكَهدارنده

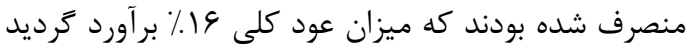

كه مشخصات دموكر افيك آنان به شرح ذيل مى باشد

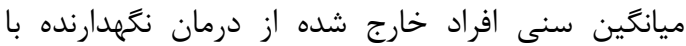

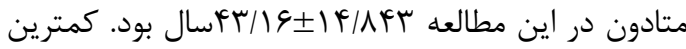
سن بيماران مورد بررسى 19 سال و بيشترين AV سال بود

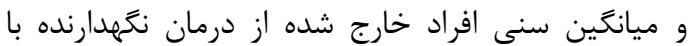
بويره نورفين در اين مطالعه 19/4

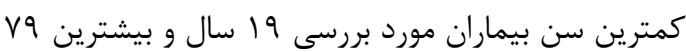
سال بود و ميانگين سنى افراد خارج شده از درمان

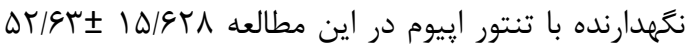

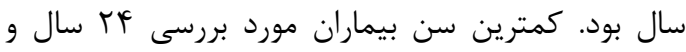
بيشترين V\& سال بود · بيشتر افراد خارج شده از درمان لردان

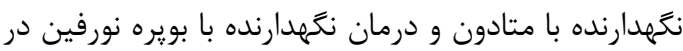

بر طبق كزارش ستاد مبارزه با مواد مخدر كشور، در حال

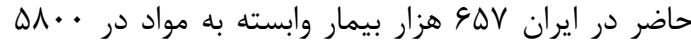

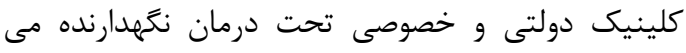

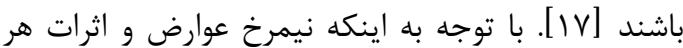

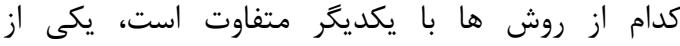
يرسشهاى مههم اين است كه درصد ماندكارى در هر يك از از

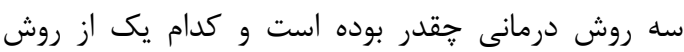
هاى درمانى ميزان موفقيت بالاترى دارد. با توجه به اينكه

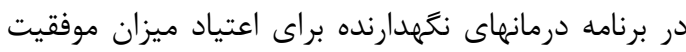
بر اساس كاهش آسيبهاى جسمى، خانوادكى و اجتماعى نئى اعتياد اندازه كيرى مى شود. شاخص عدم مصرف مواد و

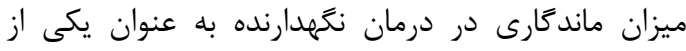

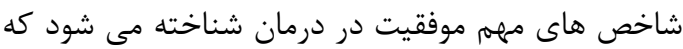

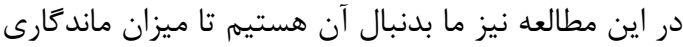

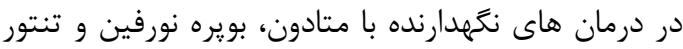

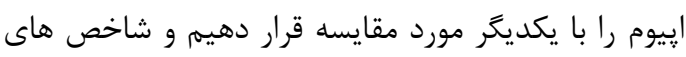
دموكر افيك و نوع ماده مصرفى افراد عود كرده در هر كروها

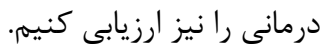

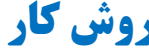

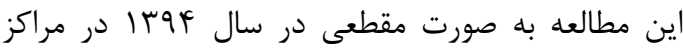
درمان اعتياد شهرستان شيروان استان خراسان شمالى به دانه

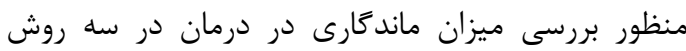

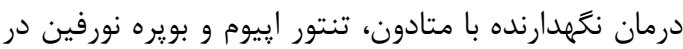

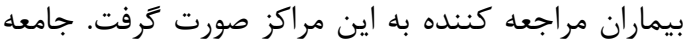

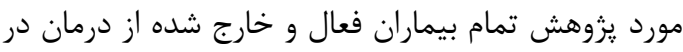

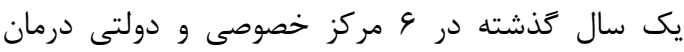
اعتياد شهرستان شيروان بود. از كليه بيماران واجد شرايط درخواست همكارى شد. اين مطالعه به صورت نمونه كيرى

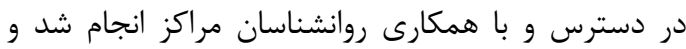

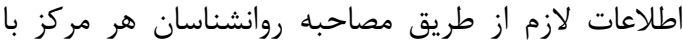

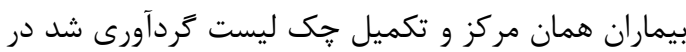

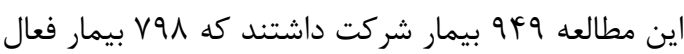
در طول يكسال كذشته تحت درمان بودند و الها بيمار از

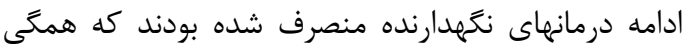
وارد مطالعه شدند. متغيرهاى مورد بررسى در اين يزوهش علاوه بر متغيرهاى

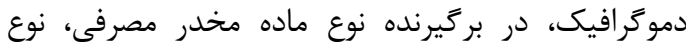




\begin{tabular}{|c|c|c|}
\hline تعداد(درصد) & جنسيت & نوع درمان نتَهدارنده \\
\hline$(\wedge \vee / 9) \wedge \vee$ & 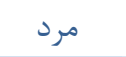 & درمان نكهدارنده با متادون \\
\hline$(I T / 1) I T$ & زن ان & \\
\hline$(1 \cdots) 99$ & كل & \\
\hline$(\Lambda \vee / q) r q$ & 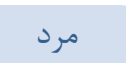 & درمان نكمهدارنده با بويره نورفين \\
\hline$(\mid r / I)^{F}$ & 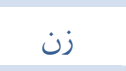 & \\
\hline سץ(• (1) & كل & \\
\hline$(\vee \wedge / 9) \backslash Q$ & 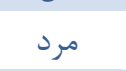 & درمان نتمهدارنده با تنتور إيوم \\
\hline$(Y I / I))^{r}$ & زن & \\
\hline$(1 \cdots) 19$ & 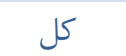 & \\
\hline
\end{tabular}

\begin{tabular}{|c|c|c|}
\hline تعداد(درصد) & تحصيلات & نوع درمان نكهدارنده \\
\hline$(/ / q q / \Delta) \& q$ & بى سواد-ابتدايى & درمان نكَهدارنده بامتادون \\
\hline سז(Y) & راهنمايى_دبيرستان & \\
\hline$(/ .11 / 1) 11$ & دييلم & \\
\hline$(1.9)^{9}$ & دانشعاهى & \\
\hline$(/ .1 \cdots) 99$ & 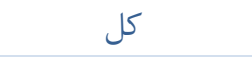 & \\
\hline | & بى سواد-ابتدايى & درمان نكَهدارنده با بويره نورفين \\
\hline$(/ . r / / T) V$ & راهنمايى-دبيرستان & \\
\hline ( & دييلم & \\
\hline$(/ .1 T / 1)^{F}$ & دانشخاهى & \\
\hline r זr(•) & كل & \\
\hline$(/ . r) / 9) \varphi$ & بى سواد-ابتدايى & درمان نكَهدارنده با تنتور إيوم \\
\hline$(/ . \Gamma / / 9) \varphi$ & راهنمايى_دبيرستان & \\
\hline$(/ . / 1 / 8) \varphi$ & دييلم & \\
\hline$(/ . \Delta / T))$ & دانشخاهى & \\
\hline$(/ .1 \cdots) 19$ & 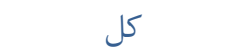 & \\
\hline
\end{tabular}


جدول rا: توزيع بيماران خارج شده از درمانهاى نكَهدارنده به تفكيك نوع درمان و محل سكونت

\begin{tabular}{|c|c|c|}
\hline تعداد(درصد) & محل سكونت & نوع درمان نتخهدارنده \\
\hline$(99 / V) \& 9$ & شهر & درمان نتحهدارنده با متادون \\
\hline$(r \cdot / \mu) \mu \cdot$ & 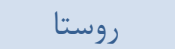 & \\
\hline$(1 \cdots) 99$ & 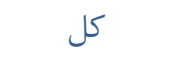 & \\
\hline$(\Lambda) / \Lambda) Y V$ & شهر & درمان نكهدارنده با بويره نورفين \\
\hline$(1 \Lambda / T) \varphi$ & 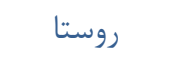 & \\
\hline זr( • (1) & 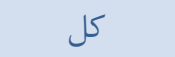 & \\
\hline$(\Lambda F / T) \backslash \varepsilon$ & شهر & درمان نخههدارنده با تنتور إييوم \\
\hline$(1 \Delta / \Lambda) r$ & 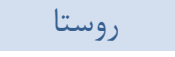 & \\
\hline$(1 \cdots) 19$ & كل ال & \\
\hline
\end{tabular}

جدول f: توزيع بيماران خارج شده از درمانهاى نتحهدارنده به تفكيك نوع درمان و وضعيت اشتغال

\begin{tabular}{|c|c|c|}
\hline تعداد(درصد) & وضعيت اشتغال & نوع درمان نكهيدارنده \\
\hline$(\Lambda \cdot \mid \Lambda) \Lambda$ & شاغل & درمان نتخهدارنده با متادون \\
\hline r) & بيكار & \\
\hline$(\mid r / T) \mid T$ & خانه دار & \\
\hline$(\varphi) f$ & بازنشسته & \\
\hline$(1 \cdots) 99$ & 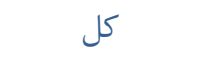 & \\
\hline$(V \wedge / \Lambda) Y G$ & 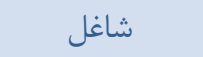 & درمان نتحهدارنده با بويره نورفين \\
\hline$(9 / 1) r$ & بيكار & \\
\hline$(\mid r / I)^{F}$ & خانه دار & \\
\hline (广)) & بازنشسته & \\
\hline זس( • (1) & 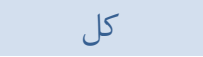 & \\
\hline$(\varepsilon N / F) \| r$ & 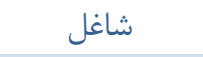 & درمان نكمهدارنده با تنتور إييوم \\
\hline$(\Delta / \Gamma))$ & بيكار & \\
\hline$(1 \cdot / \Delta) Y$ & خانه دار & \\
\hline$(1 \Delta / \Lambda) \mu$ & بازنشسته & \\
\hline$(1 \cdots) 19$ & كل & \\
\hline
\end{tabular}


جدول ه: توزيع بيماران خارج شده از درمانهاى نكَهدارنده به تفكيك نوع درمان و وضعيت تأهل

\begin{tabular}{|c|c|c|}
\hline تعداد(درصد) & وضعيت تاهل & نوع درمان نكهدارنده \\
\hline$(/ / \vee ৭ / \wedge) \vee q$ & متأهل & درمان نكهدارنده بامتادون \\
\hline$(/ .1 F / 1) / F$ & مجرد & \\
\hline$(1.9 / 1) 9$ & طلاق گرفته-بيوه-متاركه & \\
\hline$(/ .1 \cdots) 99$ & كل & \\
\hline$(/ . \Lambda F / \Lambda) Y \Lambda$ & متأهل & درمان نكهدارنده با بويره نورفين \\
\hline$(/ .1 Y / 1))^{r}$ & 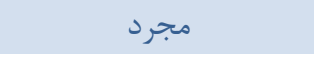 & \\
\hline$(/ . \Gamma) 1$ & طلاق گرفته-بيوه-متار كه & \\
\hline 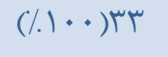 & كل & \\
\hline$(/ / \vee 9) \backslash \Delta$ & متأهل & درمان نكَهدارنده با تنتور إيوم \\
\hline$(/ .1 \cdot / \Delta) r$ & 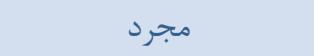 & \\
\hline$(/ .1 \cdot / \Delta) r$ & طلاق كرفته-بيوه-متاركه & \\
\hline$(/ 1 \cdots) 19$ & كل - - ال & \\
\hline
\end{tabular}

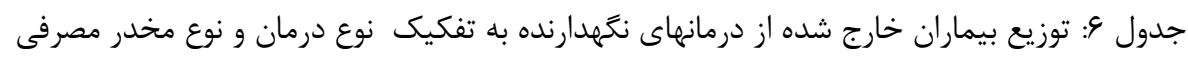

\begin{tabular}{|c|c|c|}
\hline تعداد(درصد) & نوع مخدر مصرفى & نوع درمان نتَهدارنده \\
\hline$(\Lambda F / \mathcal{F}) \wedge \mathcal{F}$ & ترياك-شيره & درمان نكَهدارنده با متادون \\
\hline$(\Lambda / 1) \Lambda$ & هرويين-كريستال & \\
\hline$(V / I) V$ & مصرف همزمان جند ماده & \\
\hline$(1 \cdots) 99$ & كل & \\
\hline (9V)Kr & ترياك-شيره & درمان نكَهدارنده با بويره نورفين \\
\hline- & هرويين-كريستال & \\
\hline (ए)) & مصرف همزمان קند ماده & \\
\hline rז) (1) & كل & \\
\hline$(1 \cdots) 19$ & ترياك-شيره & درمان نكهدارنده با تنتور إيوم \\
\hline- & هرويين-كريستال & \\
\hline- & مصرف همزمان خند ماده & \\
\hline$(1 \cdots) 19$ & كل & \\
\hline
\end{tabular}




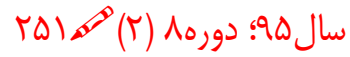

مجله دانشگَاه علوم يزشكى خراسان شمالى

جدول V: مقايسه ميزان ماندكارى در درمان در سه روش درمان نكَهدارنده با متادون، بويره نورفين و تنتور اييوم

\begin{tabular}{|c|c|c|c|c|c|c|}
\hline$P$ value & دردارج شده بيماران & خارج شده از & در در درمان & في فعال(تحت & تعداد كل & نوع درمان نكَهدارنده \\
\hline \multirow[t]{3}{*}{$\cdot 1 \cdot \cdots 1$} & $\% 1 Q / \uparrow^{c}$ & 99 & $\% \wedge r / \Delta$ & $\Delta F I$ & st. & درمان نكهيدارنده با متادون \\
\hline & $\% /$ rN/T & r & $\% \vee \backslash / \Lambda$ & NF & $11 \mathrm{~V}$ & درمان نكَهدارنده با بويره نورفين \\
\hline & $\% .9 .9$ & 19 & $\% 9 \cdot / 1$ & IVr & 195 & درمان نكهدارنده با تنتور إييوم \\
\hline
\end{tabular}

بيشتر افراد خارج شده از درمان نكمهدارنده با متادون، بويره

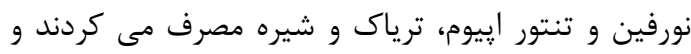
مصرف هرويين-كريستال و مصرف همزمان خند ماند ماده در

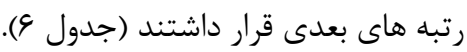

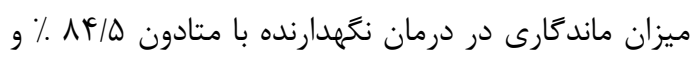

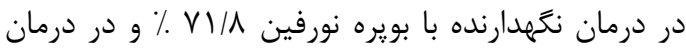

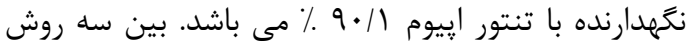

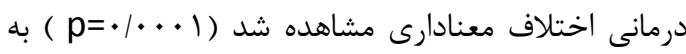

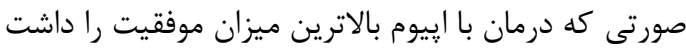

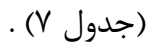

نتايج مطالعه ما نشان مى دهد كه ميزان ماندگارى در

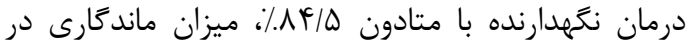

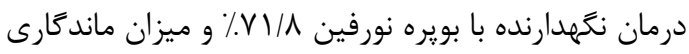

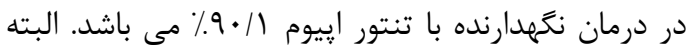

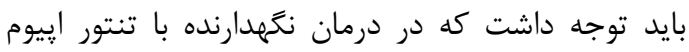

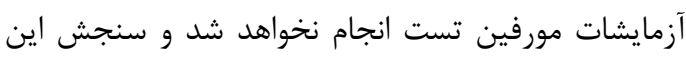

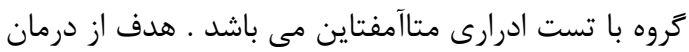

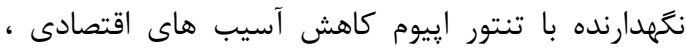

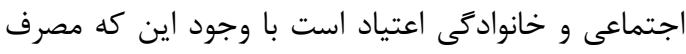

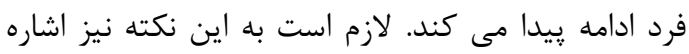

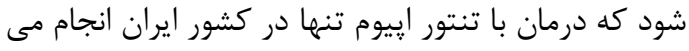

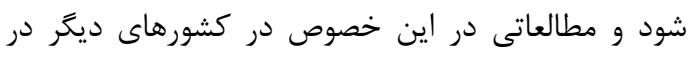

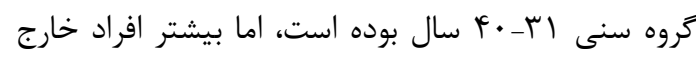

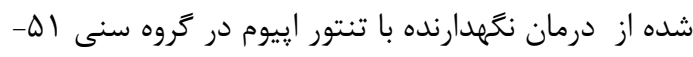

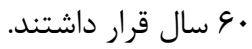

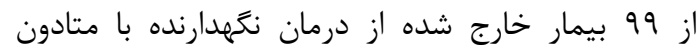

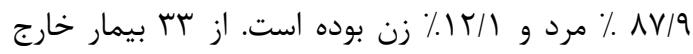

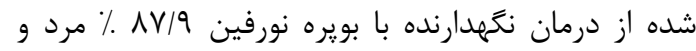

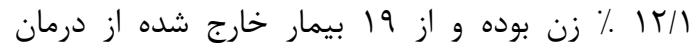

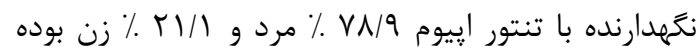
است(جدول ()).

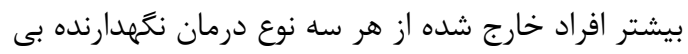

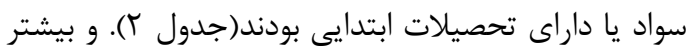

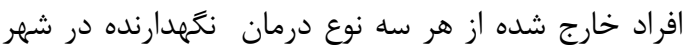

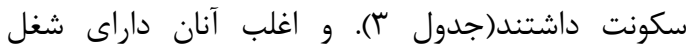

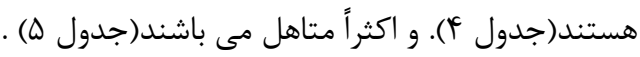

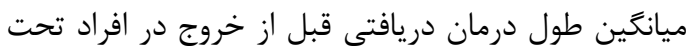

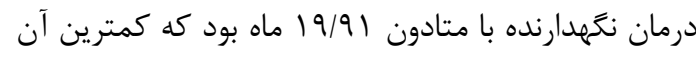

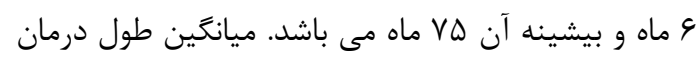

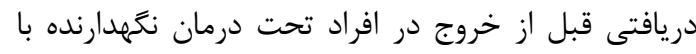

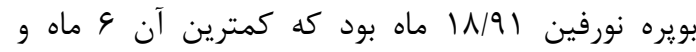

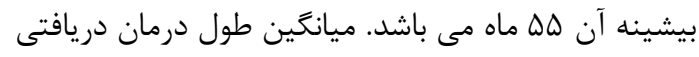

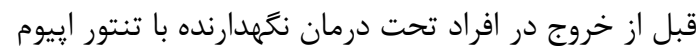

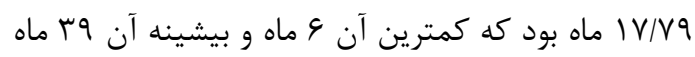

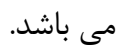


دريافت كننده ى متادون، بويره نورفين و تنتور إييوم رال شامل مى شد كه از درمان خارج شده بودند ولى نمونه

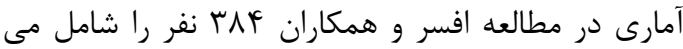

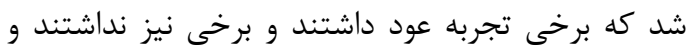

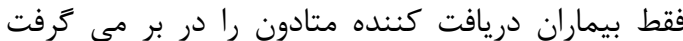

[19]

در مطالعه ما توزيع جنسى بيمارانى كه از درمان

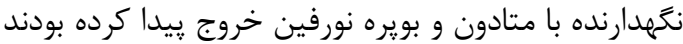

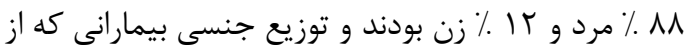

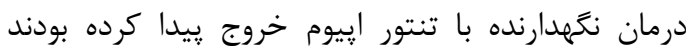

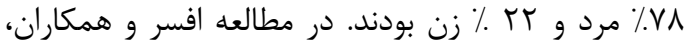

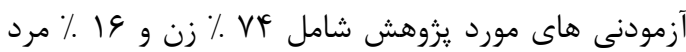

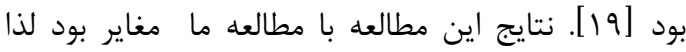
دليل آن ممكن است بخاطر تفاوت در تعداد جمعيت مورد مطالعه، تفاوت در شيوه نمونه كيرى در دو مطالعه باشد به به ديه

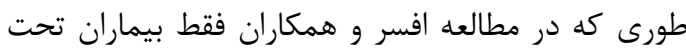
درمان نكمهدارنده با متادون مورد بررسى قرار كرفتيند.

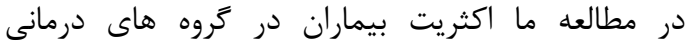
متادون، بويره نورفين و تنتور إيوم از لحاظ تحصيلى كم

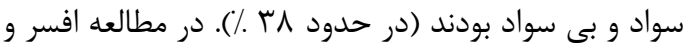
همكاران، نيز اغلب بيماران از لحاظ تحصيلى بى سواد و

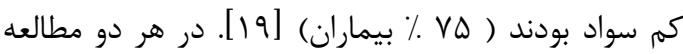

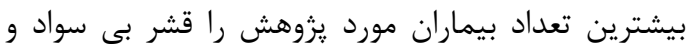
كم سواد در بر مى كرفت ولى اين ميزان در مطالعه افسر

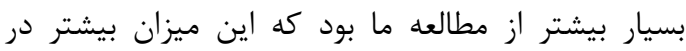

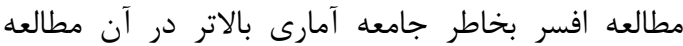

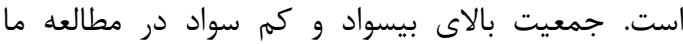

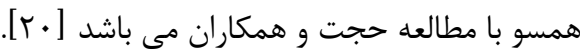
در مطالعه ما بيشتر افراد خارج شده از هر سه نوع دران داندان

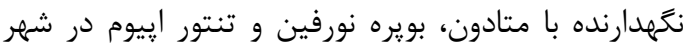

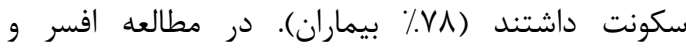
همكاران كه بر روى بيمارانى كه تجربه عود داشتند انجام

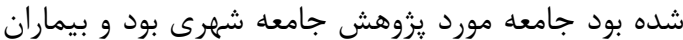

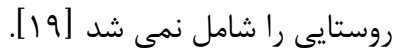

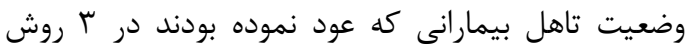

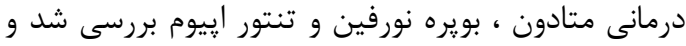

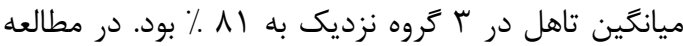

دسترس نمى باشد و در واقع سنجش ميزان موفقيت در اين روش از موضوعات جالش برانكيز مى باشد.

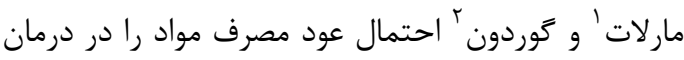

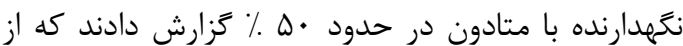

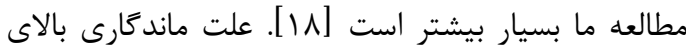
بيماران در مطالعه ما مى تواند به دليل تفاوت در انتخاب

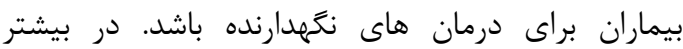
مطالعات خارجى بيماران مصرف كننده هرويين كانديد

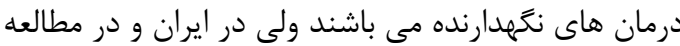
ما اغلب بيماران مصرف شيره و ترياك دارند و شايد قابل دان

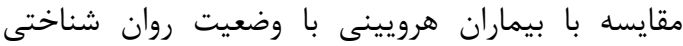

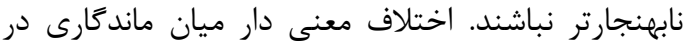

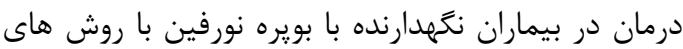

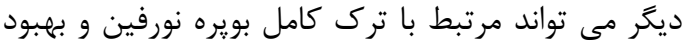

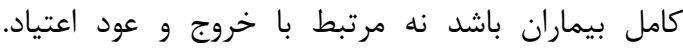
بسيارى از بيماران تحت درمان بويره نورفين ميزان مصرف باند

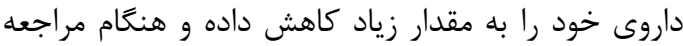
به مراكز تعداد زيادى قرص تحويل كرفته و جنداد

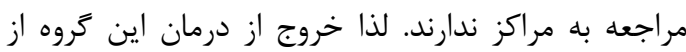
بيماران به دليل عدم مراجعه، مى تواند توجيه كننده نرخ آندان بيشتر خروج از درمان در اين روش باشد و به به معناى شكست در درمان نيست. در مطالعه ما ميانگين سنى بيمارانى كه از درمانهاى دئس نكمهدارنده با متادون و بويره نورفين خروج ييدا كرده بودند

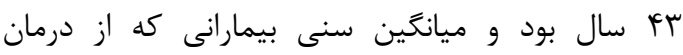

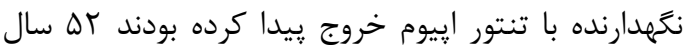

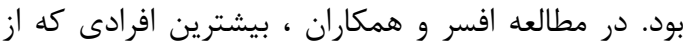

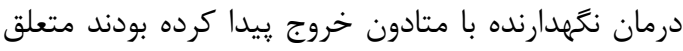

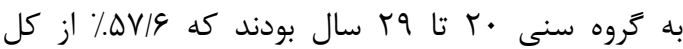
ميزان عود ها را شامل مى شد [19] اين يافته با تروهش بره

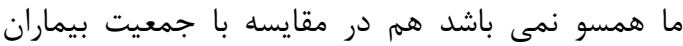
دريافت كننده متادون و هم در مقايسه با جمعيت بيماران دريافت كننده بويره نورفين و تنتور إيبوم. اين عدم تطابق

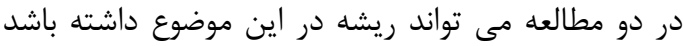

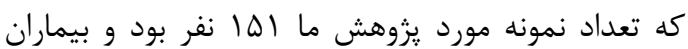

1 -Marlatt

2- Gordon 
نتخهدارنده با بويره نورفين |N/9| ماه بود كه كمترين آن

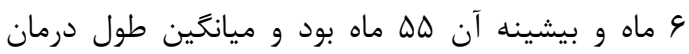

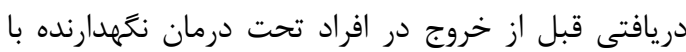

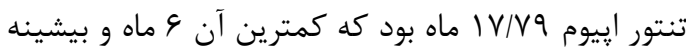

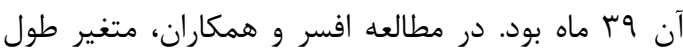
مدت تحت درمان و سابقه عود مجدد بررسى شد و ونتايج

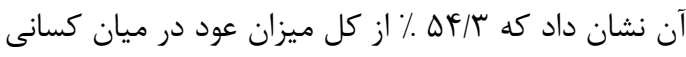

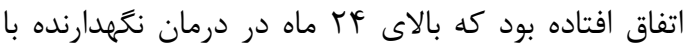

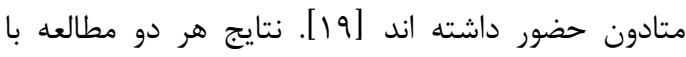

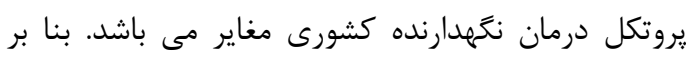

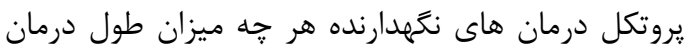

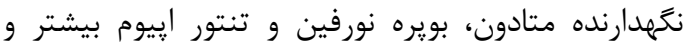

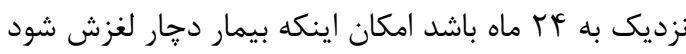

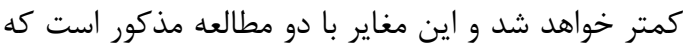

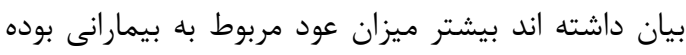

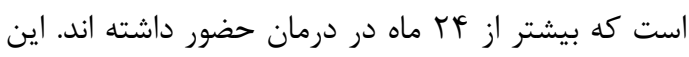
عدم تطابق مى تواند ريشه در عوامل خندى داشته داشه داشد،

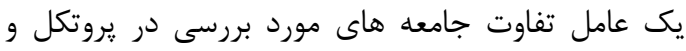

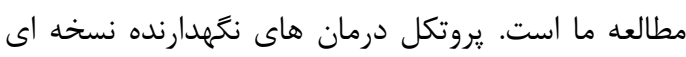

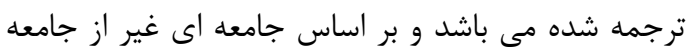

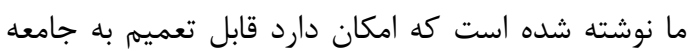

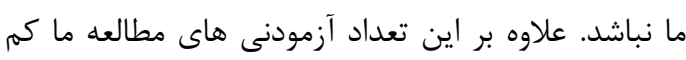
مى باشد و قابل تعميم به تمام بيمارانى نيست كلد كه تحت

$$
\text { درمان نكهدارنده به سر مى بر برند. }
$$

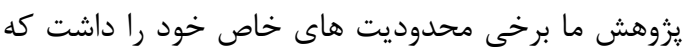

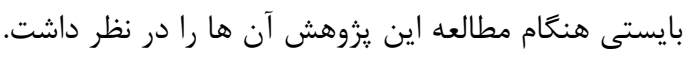

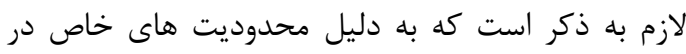
معيار هاى ورود به درمانهاى نكخهدارنده با متادون، بويره

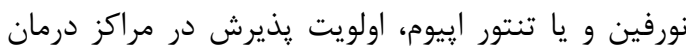

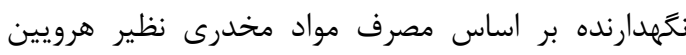

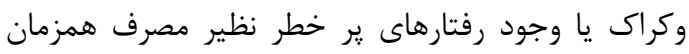

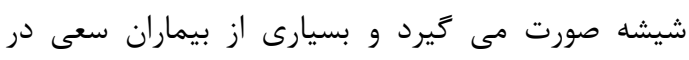

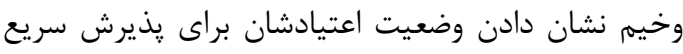
تر و يا كسب سهميه داروى نكَهدارنده با دوز بالاتر دارند.

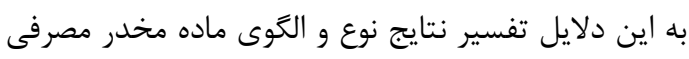

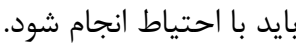

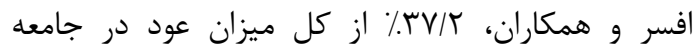

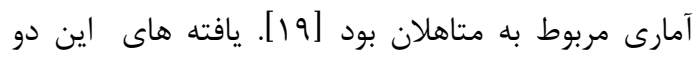

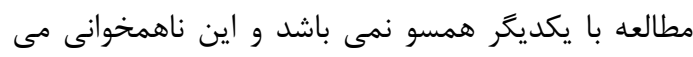

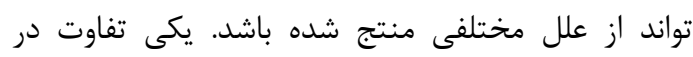

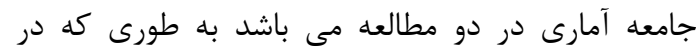

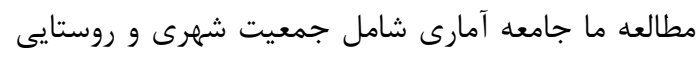
بود ولى در مطالعه افسر و همكاران، جامعه آمارى تنها ماريا

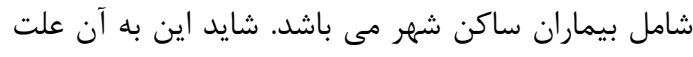

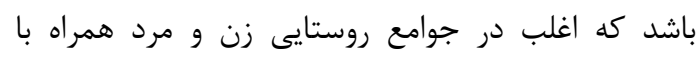

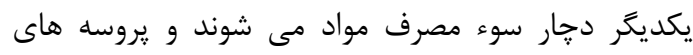

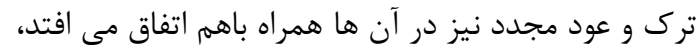

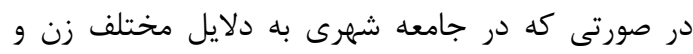

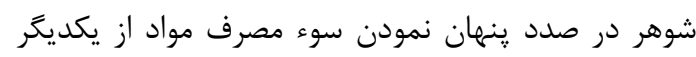

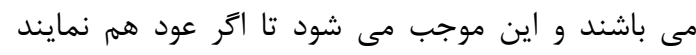

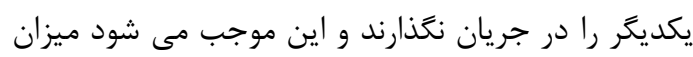

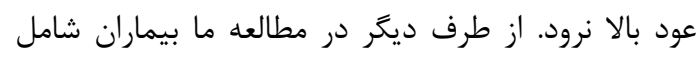

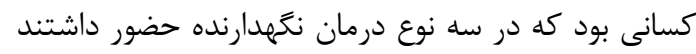

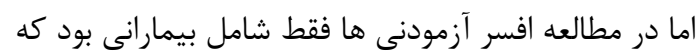

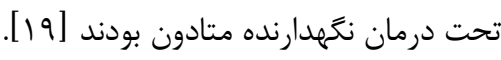

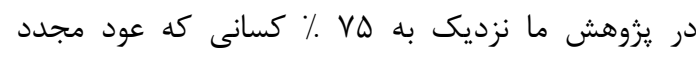

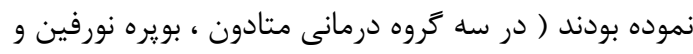

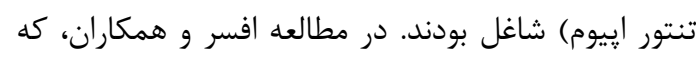

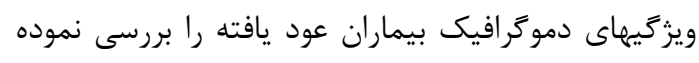

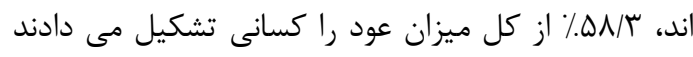

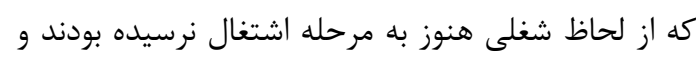

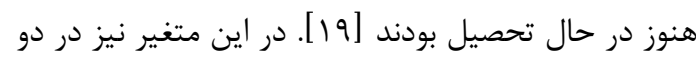

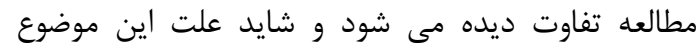

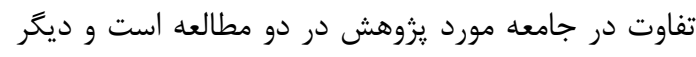

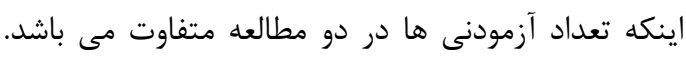

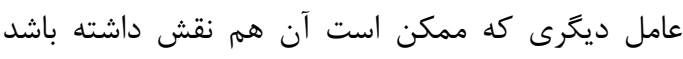

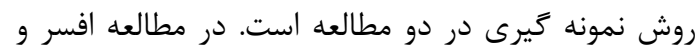

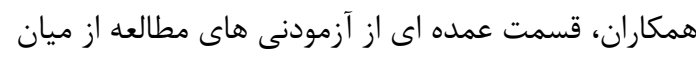
دانشجويان و افراد در حال تحصيل بوده است.

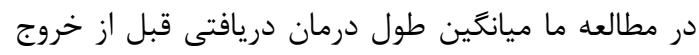

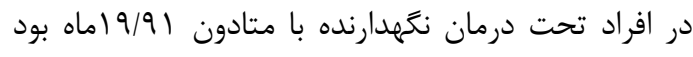

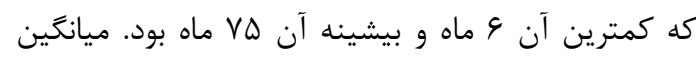

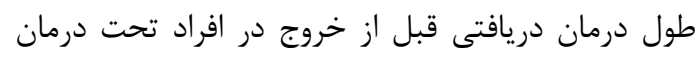


نتايج اين تحقيق نشان داد كه ميزان ماندگارى در درمان

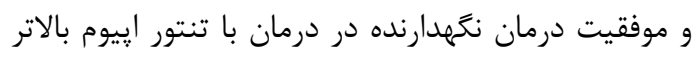

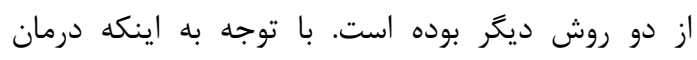

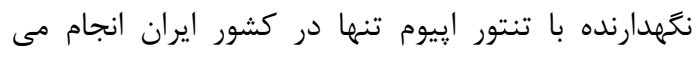

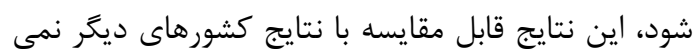

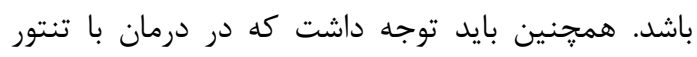

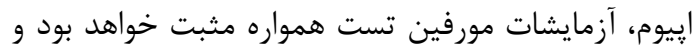

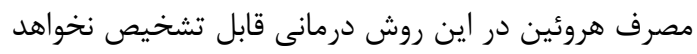

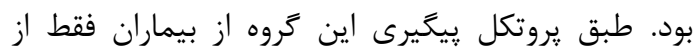

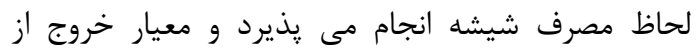

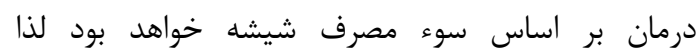

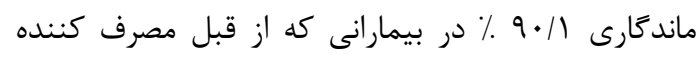

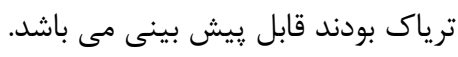

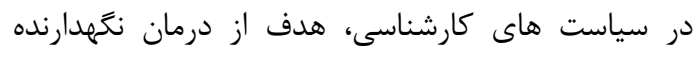

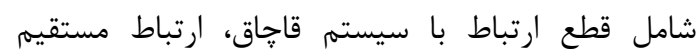
بيماران با سيستم هاى بهداشتى - درمانى، كاهش هزينه

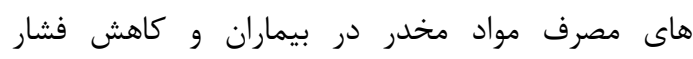
اقتصادى بر روى خانواده هاى بيماران دركير اعتياد و در در دران

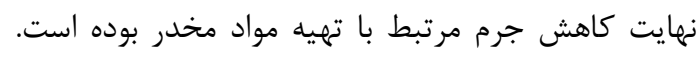

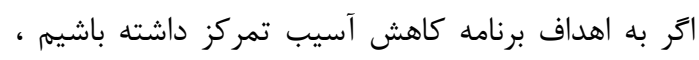

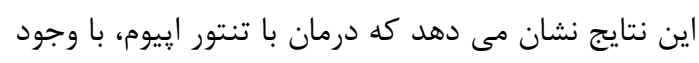

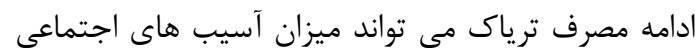

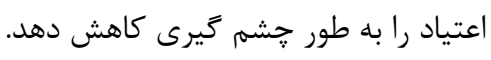

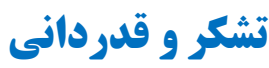

اين مطالعه با همكارى مراكز درمان اعتياد در شهرستان

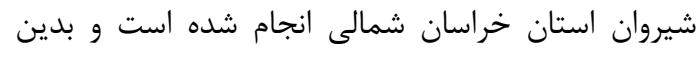

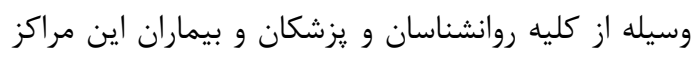

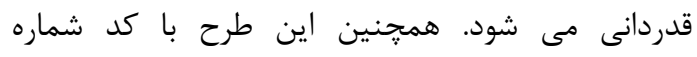

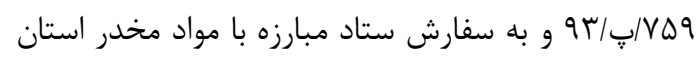

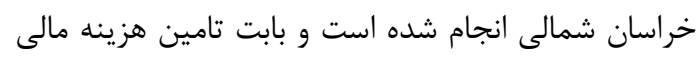

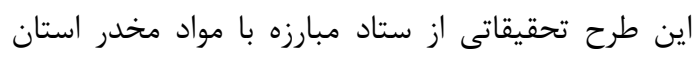

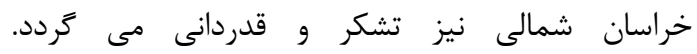




\section{References}

1. Rahnama, Ruyan, Minoo Mohraz, Ali Mirzazadeh, George Rutherford, Willi McFarland, Gholamreza Akbari and Mohsen Malekinejad, "Access to harm reduction programs among persons who inject drugs: findings from a respondent-driven sampling survey in Tehran, Iran," International Journal of Drug Policy 25, no. 4, 2014; 717-723[Persian].

2. United Nations Office on Drugs and Crime, World drug report 2010: United Nations Publications; 2010.

3. Aflatoonian MR, Sharifi I, Parizi MH, Fekri AR, Aflatoonian B, Sharifi M, "et al", A prospective cohort study of cutaneous leishmaniasis risk and opium addiction in south eastern Iran, PloS one, 2014;9(2):e89043[Persian].

4. Alam-mehrjerdi Z, Abdollahi M, Higgs P, Dolan K, Drug use treatment and harm reduction programs in Iran: a unique model of health in the most populated Persian Gulf country, Asian journal of psychiatry 2015;16:78-83.

5. Abuse S, Mental Health Services Administration (SAMHSA),(2006) National Survey on Drug Use \& Health, US Government Printing Office Retrieved from http://www oas samhsa gov/nhsda htm. 2012.

6. Robertson K, The European MonitoringCentre for Drugs and Drug Addiction, European Journal on Criminal Policy and Research, 1998;6(3):457-66.

7. Strathdee SA, Palepu A, Cornelisse PG, Yip B, O'Shaughnessy MV, Montaner JS, "et al", Barriers to use of free antiretroviral therapy in injection drug users, Jama. 1998;280(6):547-9.

8. Riksheim M, Gossop M, Clausen T, From methadone to buprenorphine: changes during a 10year period within a national opioid maintenance treatment programme, Journal of substance abuse treatment 2014;46(3):291-4.

9. Delorme J, Chenaf C, Kabore J-L, Pereira B, Mulliez A, Tremey A, "et al”, Incidence of high dosage buprenorphine and methadone shopping behavior in a retrospective cohort of opioid-maintained patients in France, Drug and alcohol dependence, 2016;162:99-106.

10. Barnett PG, Rodgers JH, Bloch DA, A meta-analysis comparing buprenorphine to methadone for treatment of opiate dependence, Addiction 2001;96(5):683-90.

11.Dolan KA, Shearer J, MacDonald M, Mattick RP, Hall W, Wodak AD, A randomised controlled trial ofmethadone maintenance treatment versus wait list control in an Australian prison system, Drug and alcohol dependence, 2003;72(1):59-65.

12. Burns L, Randall D, Hall WD, Law M, Butler T, Bell J, “ et al”, Opioid agonist pharmacotherapy in New South Wales from 1985 to 2006: patient characteristics and patterns and predictors of treatment retention, Addiction. 2009;104(8):1363-72.

13. Mattick RP, Breen C, Kimber J, Davoli M, Buprenorphine maintenance versus placebo or methadone maintenance for opioid dependence, The cochrane library 2014.

14. Auriacombe M, Fatséas M, Dubernet J, Daulouede J-P, Tignol J, French field experience with buprenorphine, American Journal on Addictions 2004;13(sup1):S17-S28.

15. Afkhami AA, From punishment to harm reduction: resecularization of addiction in contemporary Iran, Contemporary Iran: economy, society, politics 2009:194-210.

16. Berjas F, Govari F, Mohammad AZS, Haghdoost AA, The opinions of hospitalized addicts in Kerman rehabilitation centers about factors affecting theirtendency toward drugs 2011.

17. Moghanibashi-Mansourieh A, Deilamizade A, The state of data collection on addiction in Iran, Addiction, 2014; 109(5):854.

18. Marlatt G, Gordon J, Relapse prevention: maintenance strategies in the treatment of addictive disorders, New York: Guilford, 1985.

19. Afsar A, Bashirian S, Poorolaja J, Hazavehei SM, Vatan Nawaz E, Zinat Motlagh F, Predictive factors of relapse among patients treated with methadone maintenance treatment referred to addiction centers in Hamadan based on health belief model, J Health Syst Res 2014; Health Education supplement: 2034-2045. 20. Hojjat Sk, Tabatabaeichehr M,Mortazavi H, Ebrahimi sani E, Moradian H ,jafari JThe comparison of the, psychological profile of patients on methadone maintenance treatment and opiate dependent persons in bojnurd, Journal of North Khorasan University of Medical Sciences, Winter 2012;4(4):562. 


\title{
The comparison of Retention in three methods with Methadone, opium and Buprenorphine in patients admitted to addiction treatment centers
}

\author{
Hojjat $S k^{1}$, Rezaei $M^{2}$, mohamadipoor $M^{3}$, Norozi Khalili $M^{4}$, Danesh $M^{5}$, Hatami $S E^{6} *$
}

${ }^{1}$ MD, Psychiatrist, Assistant Professor, Addiction and Behavioral Sciences Research Center , North Khorasan University of Medical Sciences. Bojnurd, Iran

${ }^{2}$ MA of Clinical Psychology, Addiction and Behavioral Sciences Research Center, North Khorasan University of Medical Sciences, Bojnurd, Iran

${ }^{3}$ Assistant Professor,Department of Psychology, Ghouchan Branch ,Islamic Azad University , Ghouchan , Iran

${ }^{4} \mathrm{MD}$, Department of Community Medicine and Ethics, Faculty of Medicine, North Khorasan University of MedicalSciences, Bojnurd, Iran

${ }^{5}$ PHD student of counseling,Department of Psychology and Counseling, Bojnourd Branch ,Islamic Azad University , Bojnourd, Iran

${ }^{6} \mathrm{MSc}$ of Epidemiology, Addiction and Behavioral Sciences Research Center, North Khorasan University of Medical Sciences, Bojnurd, Iran.

*Corresponding Author: Addiction and Behavioral Sciences Research Center, North khorasan University of Medical Sciences, Bojnurd, Iran.

Email: ss_hatami2011@yahoo.com

\section{Abstract}

Background \& Objectives: According to the report by Iran Drug Control Headquarters, 657 thousand drug-dependent patients are under maintained treatment in Iran. The aim of present study was investigation of treatment-retention in patients who were undergone the maintained therapy using Methadone, Buprenorphine, and opium tincture in Shirvan city. It should be noted that the treatment with opium tincture is done only in Iran. Therefore, the success of this method is a controversial issue.

Material \& Methods: This is an analytical-descriptive study. The population of this study were included all active patients and also patients who have abandoned treatment in 6 public and private addiction treatment centers of Shirvan city in 1394. Data were analyzed by SPSS software, and chi-square test was used to compare the qualitative variables.

Results: Retention rate of Methadone, Buprenorphine, and opium treatments were $84.5 \%, 71.7 \%$, and $90.1 \%$, respectively. A significant difference was observed among these treatments, so the opium maintained treatment has the highest retention rate.

Conclusion: The results revealed that the retention rate in treatment with opium tincture is higher than that in the other two methods. If we focus on the goals of harm reduction programs, results show that the opium tinctures treatment can reduce significantly the amount of social damage.

Keywords: Methadone, Buprenorphine, opium tincture, treatment outcomes. 